\title{
Evaluating Elizabeth Grosz's Biological Turn
}

\author{
ROSE TRAPPES ID
}

Elizabeth Grosz's interpretation of Darwinian evolutionary theory to ground a feminist ontology of biology has been particularly controversial. Most critics have understood Grosz as supporting her theory with empirical evidence, and they criticize her for being either inaccurate or uncritical of and overly dependent on science. I argue that Grosz reads Darwin as a philosopher in a Deleuzian and Irigarayan sense, and that Grosz's project is therefore better understood in terms of its ethical and political goals rather than in terms of empirical adequacy. Employing this evaluative framework leads to a novel route for critique of Grosz's ontology in terms of its reliance on the Darwinian distinction between organism and environment. I conclude that Grosz's work is valuable for the way it maintains ethical and political considerations in feminist ontological debates, and that introducing a more sensitive understanding of the organism-environment relation will lead us closer to a truly feminist ontology of biology.

Elizabeth Grosz's work since the late 1990s has exhibited what one could call a "turn to biology." Using the work of Charles Darwin, in addition to that of Gilles Deleuze, Henri Bergson, Friedrich Nietzsche, and Luce Irigaray, Grosz develops an ontology of biology as dynamic, unpredictable, and sexually differentiated. In this article I argue that commentators generally understand Grosz's turn to biology to involve a simultaneous turn to what I term methodological naturalism. In other words, by using Darwinian evolutionary theory as the basis for an ontology of biological matter, Grosz seems to uphold the belief that philosophy should align itself with science and thus ground itself on empirical data. Based on this interpretation of Grosz as a methodological naturalist, many critics have rejected her account either as empirically inaccurate, or, alternatively, as insufficiently critical and overly dependent on empirical facts. In contrast, by reevaluating Grosz's methodological approach, I argue that her ontology of biology must be reevaluated according to ethical and political standards, not empirical ones. In this way, I develop a novel criticism of Grosz's ontology of biology, namely that it relies on a distinction between organism and environment 
that is problematic on feminist ethical and political grounds. Introducing a more sensitive understanding of the organism-environment relationship, I suggest, is crucial in producing a truly feminist ontology of biology.

Before I begin, it is necessary to clarify a few terms. First, it is worth noting that "biology" is an ambiguous term, referring both to the science that studies living matter and to living matter itself. In this article I use the terms "biological science(s)" and "biological matter" to disambiguate. Here I diverge from Grosz: though she acknowledges the ambiguity of the term, she persists in using "biology" to refer to biological matter (Grosz 2005, 13; cf. McNeil 2010, 436). Second, though ontology is never an easy term to define, the ontology of biology refers here to the study of the nature or being of biological matter. As such, in developing an ontology of biology, Grosz seeks to provide a characterization of what it is for biological matter to be biological matter.

It is also worth noting the scope of Grosz's ontology that I consider here. Grosz's work since the 1990s aims to develop a general ontology that could apply to all being, what Tuija Pulkkinen calls a "grand project of ontology" (Pulkkinen 2017, 289). However, Grosz begins with a more restricted ontology of living being or biological matter, gathered primarily from her reading of Darwin's theory of evolution. She later extends and develops this regional ontology through readings of Bergson, Nietzsche, and Deleuze to an ontology of materiality and sociality more generally (Grosz 2011, 4). Whether and how Grosz successfully extends a regional ontology of biology to a more general ontology is a question I do not consider here (but see Pulkkinen 2017). Instead, I focus only on her more restricted ontology of biological matter. This restricted focus enables me to develop an understanding of Grosz's ontology of biology as well as her methodological approach in a way that sheds new light on her project in general and enables me to formulate a novel criticism.

I begin by summarizing Grosz's general ontology of biology as the continual, unpredictable generation of difference and her introduction of sexual difference to her ontology of biology. Next, I discuss the criticisms Grosz has received for her ontology and argue that Grosz's critics often interpret her to be a methodological naturalist. I then show that Grosz's Deleuzian and Irigarayan heritage inflects her methodological approach such that she aims not for empirical accuracy but rather for ethical and political effectiveness. Finally, I briefly evaluate Grosz's project in light of her ethical and political goals. I argue that Grosz's reliance on the Darwinian understanding of the organism in contrast to its environment is inappropriate for a feminist ontology of biology and make some suggestions for how this understanding could be revised. I conclude by suggesting that, despite its drawbacks, Grosz's work represents a valuable contribution to the current wave of new feminist ontologies due to its explicitly feminist ethical and political character.

\section{Grosz's Ontology of Biology}

Elizabeth Grosz has long been interested in the matter of biology. Already in Volatile Bodies, Grosz claimed that constructing a feminist philosophy of the body that can 
challenge biological determinism and essentialism requires rethinking biological matter and the category of the natural (Grosz 1994). This project came to the fore in her works Nick of Time, Time Travels, and Becoming Undone (Grosz 2004, 2005, 2011), in which she seeks to understand "how the biological prefigures and makes possible the various permutations of life that constitute natural, social, and cultural existence" (Grosz 2004, 1). A primary resource for her ontology of biology throughout her turn to biology is Darwin's evolutionary theory, especially his theories of natural selection and sexual selection. As it forms the basis of Grosz's ontology of biology, it is worth giving a brief sketch of Darwin's evolutionary theory.

Darwin's theory of how species evolve and change over time revolutionized the contemporary understanding of biology. Though Darwin was not the only theorist to posit the gradual change and development of species as we currently know them, his theory of evolution was one of the most comprehensive and coherent theories of evolution at the time, and it certainly proved to be the most influential (Jablonka and Lamb 2014, chapter 1).

Darwin's theory of natural selection is often summarized as "the survival of the fittest." Though crude, this captures the basics. Essentially, for Darwin, there are many different individuals, each with a different ability to reproduce itself within a certain environment, that is, each with a different fitness level. The individuals who can reproduce themselves better (who are more fit) have more offspring than the others. If this fitness is heritable (if it is passed on to the offspring more than would be dictated by chance), the offspring, too, are more likely to have more offspring that themselves survive to produce ever more offspring. So over successive generations, the better-producing types of individuals (the fit ones) start to outnumber the others. Eventually, the fitter type of individuals comes to dominate a population, meaning that the norm for that population becomes whatever characterizes the fitter type. In this way, the characteristics of a species change over time. Moreover, since there are many different environments and fitness is relative to environment, different species will evolve differently depending on where they are and what is available to them. Hence the great diversity of life on the planet.

This kind of model of evolution, as I have roughly sketched it, is debated extensively in the philosophy and theory of biology, and Darwin's theory is usually not accepted without at least addition or modification of some of its aspects, and often with far more significant alteration (Godfrey-Smith 2014, chapter 3; Jablonka and Lamb 2014). But for Grosz, the details are less important than the basic principles and the understanding of biological matter that can be derived from them.

Specifically, Grosz highlights two features of life in Darwin's theory that she finds particularly significant. The first is that his theory of evolution is premised on the existence and continual production of difference (Grosz 2004, 18). Without differences among individuals, there could be no differential survival and reproduction of certain individuals and thus no evolution. As well as requiring diversity, evolution often produces difference: species often become more different through evolutionthough it is worth noting that this is not always the case, since there is convergent evolution where organisms become more alike. ${ }^{1}$ The second feature Grosz picks out 
is that evolution for Darwin is based on probability. Fitter individuals are only likely to produce more offspring than less fit individuals, but they may not, and offspring are only likely to inherit the fitness of their parents, but they may not. Evolution therefore includes an element of unpredictability (33).

Grosz suggests that the continuous, unpredictable production of difference evidenced in Darwin's theory is the essence of biological matter, that is, what sets biological matter apart from nonliving matter. Biological matter is characterized, for Grosz, by "the dynamism, growth, and transformability of living systems, indeed the impossibility of stasis and mere reproduction, the impulse toward a future that is unknown in and uncontained by the present and its history" (32). Thus, Grosz concludes, "it is only differentiating, distinguishing, rendering more distinct, specializing and adapting that characterize life in its essence. Its essence is in differentiation, in making a difference" (46). This, then, is the basis for Grosz's ontology of biology: biological matter is the dynamic, unpredictable production of difference.

Thus, one of Darwin's most valuable insights, for Grosz, is the way in which he understood life as the elaboration of difference. Based on her reading of Darwin, Grosz maintains that "life must be understood as the ongoing exploration of and experimentation with the forms of bodily activity that living things are capable of undertaking" (Grosz 2011, 22). The centering of biological matter on dynamism and change is itself already a significant basis for an ontology, but Grosz does not stop there. Turning to Darwin's work on sexual selection, she expands her ontology to also incorporate sexual difference as an essential aspect of biological matter.

Grosz's primary reference points for her discussion of sexual difference are two theories about the evolution of sexual reproduction and differentiation. The first theory concerns the evolution of sexual reproduction. Sexual reproduction brings two different gametes, the egg and the sperm, together to form a new individual. In contrast to clonal reproduction, in which there is only one parental organism that replicates itself in the next generation, sexual reproduction produces novelty through the combination of two sets of parental inheritances. This means that sexual reproduction generates offspring that are more likely to differ from their parents and from each other than the offspring produced by clonal reproduction, all other things being equal. The production of increased variation is thought to have lent an evolutionary advantage to what would otherwise be a restrictive and thus largely unfavorable mode of reproduction. And since sexual reproduction requires two sexes (two kinds of gametes), Grosz infers that "sexual bifurcation provides better resources with which natural selection can work because it induces more variation" (Grosz 2004, 69). For Grosz, then, the theory about the evolution of sexual reproduction already links sexual difference with the ontology of biology as the production of difference.

The second theory about sexual difference that Grosz draws on is Darwin's theory of sexual selection, which provides an additional and probably stronger role for sexual difference in inducing variation. Rather than the competition for resources (food, shelter, and so on), as in natural selection, sexual selection concerns the competition for mates. Darwin hypothesized that the great variety of forms in nature, and especially the existence of certain extravagant forms like showy feathers or complex bird 
calls, could only be fully explained if one sex exerted a selective pressure on the other by choosing only certain kinds of mates. The organisms who are more appealing to the choosy sex will be more likely to have more offspring, and if they pass their appeal on to their offspring, then the appealing organisms will start to become more and more common, thus changing the norm for the species. In each species this happens differently, so that each species starts to acquire different characteristics. Hence the great diversity of life on the planet.

It is now common to assimilate sexual selection into natural selection, as just another kind of criteria for reproductive success. But for Darwin, and for Grosz reading Darwin, sexual selection is a different mechanism with distinctive results. Grosz highlights three aspects of sexual selection that are particularly relevant for her ontology. First, sexual selection drives greater production of difference than natural selection. Second, sexual selection generates a wider variety of unpredictable innovations, since there is no predicting what will come to be considered attractive in a given species. Third, though maintaining that sexual selection relies on binary sexual difference, Grosz suggests that this binary is noncategorical, and that sexual selection can indeed drive the generation of more varied sexual differences: "Sexual selection differentiates all species touched by its trace with an irreducible binarism that itself generates endless variety on either side of its bifurcation, and indeed produces variations - the intersexes - that lie between bifurcated categories" (Grosz 2004, 67). Grosz therefore concludes that sexual difference, being the basis for both sexual reproduction and sexual selection, is a crucial factor in generating unpredictable differences in life.

After positing its role in generating unpredictable difference, Grosz makes two claims to support her belief that sexual difference is ontologically fundamental to biological matter. First, she states that "evolution never reverses itself" (67), and that therefore sexual difference, once developed, will never disappear. Second, Grosz states that asexually reproducing organisms are "rare cases" (69) that have traded reproductive stability for less development, specialization, and diversity and that are thus insignificant for her ontology of biology. Grosz concludes that sexual difference is an ineliminable and universal feature of biological matter.

Grosz's inclusion of sexual difference in her ontology of biology has been heavily criticized in the literature, and in the following section I briefly review these criticisms. Though I argue that her inclusion of sexual difference can be read as consistent with other aspects of her ontology of biology, I follow her critics in concluding that Grosz's position lacks empirical support. I then turn to consider whether scientific accuracy is really the right standard by which to evaluate Grosz's theory.

\section{Not Another Naturalist}

Grosz's argument that sexual difference is part of the ontology of biology has been challenged on a number of points. First, it appears to be contradictory, characterizing biological matter as totally dynamic and unpredictable while at the same time 
positing sexual difference as a necessary (and therefore unchanging and predictable) condition of biological matter. Thus, commentators like Luciana Parisi and Jami Weinstein conclude that Grosz contradicts herself when she introduces sexual difference (Parisi 2010; Weinstein 2010). Moreover, an ontology of biology as totally dynamic and unpredictable could also be seen to be inconsistent with the general idea that biological matter produces difference; without some kind of stability and regularity, and especially without the reasonably faithful inheritance of parental characteristics, the great differences with which Grosz is concerned could never have developed through evolution. This suggests that Grosz's ontology is not internally consistent.

Perhaps a more charitable reading could refer to Grosz's numerous references to regularity and constraints in nature. There are moments throughout her texts in which Grosz speaks of nature in terms of resistance (Grosz 2004, 72), cohesion (18), and constraints (33). Grosz also speaks of biological features that "rather than simply exhibit stasis, a fixed essence or unchanging characteristics, are more readily understood in terms of active vectors of change" (19; emphasis added). Thus, although Grosz at times refers to "the impossibility of stasis and mere reproduction" (32), at other times she rejects only the total characterization of biology by regularity, presenting instead an account of biology as somewhat dynamic and unpredictable. Grosz's very inclusion of sexual difference as a condition for the continual production of difference, rather than a weakness of her theory, could also be interpreted as an outline for a broader understanding of the way that some level of regularity and stability more generally is a condition for life as the production of difference. In other words, it is possible to read Grosz as more sensitive to the interplay between change and stasis, difference and repetition, than many have given her credit for or than she herself makes clear.

But this charitable reading does not address another group of critics: those who criticize Grosz's ontology as scientifically inaccurate. First, there is the simple fact that asexually reproducing organisms are not rare cases at all. As Myra Hird points out, Grosz's "big like us" perspective leads her to overlook the sheer diversity of modes of reproduction and the various ways of generating differences that asexually reproducing organisms have developed (Hird 2009a, 111). It is quite common, for instance, for bacteria to exchange genetic material with one another, creating new combinations of genetic material directly rather than through reproduction (93). Moreover, as anyone who has seen bacteria acquiring antibiotic resistance in a petri dish could attest, the rapid rate at which bacteria reproduce means that any small genetic change can easily proliferate exponentially and generate further differences. It makes little sense, then, to claim that sexual difference is the only or even the most privileged form of biological matter's continual, unpredictable production of difference.

It can also be objected that evolution can indeed "reverse itself," and that it is possible that certain kinds of evolved features can cease to be reproduced over evolutionary time. As Parisi comments, citing Stephen Gould as well as empirical studies on all-female colonies of ants, the evolution of sexual reproduction was itself an evolutionary accident that therefore implies no necessity, meaning sexual reproduction 
could very well cease to be dominant in the future (Parisi 2010, 153, 161). Thus, even if sexual difference were a privileged form of the production of difference, it is not justified to claim that sexual difference is an irreducible and ineradicable feature of biological matter.

Grosz's assertions about the ontological primacy of sexual difference in biological matter thus seem to be empirically unfounded. This has led commentators who might be sympathetic with Grosz's general ontology of biology to reject her claims regarding the ontological primacy of sexual difference (for example, Hird 2009a; Parisi 2010; Jagger 2015). It is, moreover, not difficult to extend this objection of inaccuracy to Grosz's ontology of biology more generally. Regularity and stability are familiar features of biological matter, and to deny these features in favor of an ontology in which biological matter is entirely unpredictable and always changing, it could be argued, is to fall foul of basic empirical evidence.

These critiques share a general consensus that Grosz's ontology of biology is grounded on the facts revealed by the biological sciences. A useful way to characterize this approach is as a form of methodological naturalism. ${ }^{2}$ Methodological naturalism is the belief that philosophy is just like science in that it aims to construct "synthetic theories about the natural world, answerable in the last instance to the tribunal of a posteriori empirical data" (Papineau 2016). Thus, in drawing on theories of natural and sexual selection, Grosz appears to support her philosophy through factual claims about the nature of living beings, claims that are open to being tested and accepted or rejected according to their level of empirical support.

Critics like Parisi and Hird, in contesting Grosz's claims by referring back to biological data, tend to take methodological naturalism for granted. In contrast, a number of other critics take naturalism to be a weak point of Grosz's approach to philosophy. Pulkkinen objects strongly to the way Grosz uses theory and facts from the biological sciences to support her philosophical claims (Pulkkinen 2017, 288-92). First, Pulkkinen argues, Grosz hands too much authority over to the biological sciences, reinforcing the widespread domination of the humanities by the natural sciences. For instance, Pulkkinen objects to Grosz's use of Darwin's theory of sexual selection to support the ontological status of sexual difference, which "makes Irigaray's sexual difference, which is a psychoanalytical and philosophical a priori, dependent upon facts of bio-science" (288). Second, Grosz jeopardizes the plurality that Pulkkinen argues is crucial for thinking and especially for feminist and queer theorizing. Grosz's methodological naturalism, then, is "a mode of discussion [that] introduces a sense of single and evident truth that is traditionally foreign to feminist debates and gender studies as a discipline" (290-91) Thus, Pulkkinen objects to the suitability of Grosz's methodology for independent and pluralist feminist philosophy to adopt, notwithstanding the potentially valuable headway Grosz makes toward developing a feminist ontology.

Maureen McNeil also objects to Grosz's methodological naturalism, this time on the grounds that it is overly naïve. In Grosz's affirmative approach to biological theory, McNeil observes, "the entanglements of discourse and the social practices and structures of biological science do not get a look in" (McNeil 2010, 436). Despite 
herself, Grosz seems to endorse and rely on facts revealed by the biological sciences, failing to pay critical attention to the way such facts are themselves ideologically informed and often detrimental to feminist projects, as decades of feminist science studies have shown. Since methodological naturalism reinforces knowledge hierarchies, discourages plurality, and assumes value-free scientific objectivity, it is an inappropriate approach for developing a feminist ontology.

However, there are reasons to suspect that Grosz is anything but a methodological naturalist. First, as has become evident, Grosz exhibits a distinct lack of attention to the empirical data concerning sexual difference and biological matter. It would be strange for a philosopher of her stature to ignore such data if her account depended on them. Second, Grosz combines her analysis of Darwinian theory with the thought of distinctly nonscientific theorists, including Friedrich Nietzsche, Henri Bergson, Gilles Deleuze, and Luce Irigaray. Combining Darwin with these philosophers, Grosz refers to him on numerous occasions as a philosopher or as partly responsible for developing a philosophy of becoming (for example, Grosz 2011, 3, 120). Thus, as Pulkkinen states, in Grosz's work "Darwin [is] effectively portrayed as an ontologist rather than as a life scientist" (Pulkkinen 2017, 287).

The methodological significance of Grosz reading Darwin as a philosopher has yet to be fully explored. Though they recognize the philosophical register of Grosz's interpretation of Darwin, Pulkkinen, Parisi, Hird, and others continue to interpret Grosz as a methodological naturalist, where reading Darwin as a philosopher means using empirical evidence to back up a philosophy. This is especially evident in Pulkkinen's work, where Grosz is recognized as reading Darwin as an ontologist (Pulkkinen 2017, 287-88) and a political thinker (289), but where this nevertheless amounts to appealing to scientific authority and "privileging scientific evidence" (290).

One exception to the methodological naturalist reading is Weinstein. Quite like Pulkkinen, Weinstein suggests that Grosz's theory should be assessed not according to its empirical support but according to its effect on feminist discourse (Weinstein 2010). Unlike Pulkkinen, who argues that Grosz's methodological naturalism could have potentially damaging effects on feminist philosophy, Weinstein concludes that Grosz's theory can have a positive effect. Specifically, she argues that the tension between ontological sexual difference and continual, unpredictable change in Grosz's work may be a way to work through and ultimately beyond sexual difference theory. Weinstein therefore assesses Grosz's work not in terms of its reliance on empirical data but in terms of its ability to open up a space for new developments in feminist theory.

Weinstein's approach of evaluating Grosz in nonnaturalistic terms is productive, but she remains hesitant to attribute to Grosz an intentionally nonnaturalistic method. In the next section, I show that Grosz's understanding of philosophy implies a distinction between the methods of science and the methods of philosophy. Whereas science aims to develop accounts of the world based on empirical evidence, Grosz adopts both Deleuzian and Irigarayan understandings of philosophy according to which philosophy should be assessed according to ethical and political standards. As a consequence, her philosophical reading of Darwin should not be read as 
amounting to methodological naturalism. Rather, Grosz's work with Darwin should be understood as "onto-ethics." In elaborating Grosz's understanding of the task of onto-ethics, I provide support for Weinstein's nonnaturalist reading of Grosz and set up the framework for a revised evaluation of Grosz's ontology.

\section{The TASK of Onto-ETHICS}

First and most explicitly, Grosz adopts Gilles Deleuze and Félix Guattari's idea of philosophy as the creation of new concepts that transform our field of understanding (Grosz 2010, 2011, chapter 5). Deleuze and Guattari develop their understanding of philosophy in What is Philosophy? (Deleuze and Guattari 1994), in part through a contrast between philosophy and science (Patton 1996; Smith and Protevi 2018; for a contrasting interpretation, see Butler 2016). Science, they claim, concerns the generation of propositions that correspond to the world, and can therefore be assessed based on its level of empirical support (Deleuze and Guattari 1994, 22). In contrast, philosophy involves the creation of concepts that are not assessable in terms of how well they correspond to reality, since, according to Deleuze and Guattari, they aren't about correspondence to reality at all. Instead of empirical adequacy, Deleuze and Guattari hold that a philosopher's concept can be evaluated only in terms of the way it generates a new field of understanding, complete with specific problems to which it responds and specific conceptual relations (31).

This standard of novelty bears ethical and political significance. Clare Colebrook explains that the aim of philosophy for Deleuze is to "create new ways of thinking and living," a task that has distinct political and ethical consequences (Colebrook 2002, 76). As Paul Patton puts it, Deleuze and Guattari assign philosophy “a 'utopian' task" (Patton 1996, 13) of generating a transformation in the way we understand our lives and thereby how we live in the world. A number of theorists have now elaborated the way Deleuze and Guattari took up this ethical and political task of creating transformative new concepts, developing alternatives to current models of capitalism, communism, humanism, oedipal desire, and so on (Colebrook 2002; Braidotti 2006).

Reading Darwin as a philosopher in the Deleuzian sense, Grosz understands Darwinian natural and sexual selection as concepts: together, they completely transform the way we can think about reality and the human subject. The most significant elements of Darwin's concepts, according to Grosz, include the understanding of biological matter in terms of dynamism and unpredictability (Grosz 2005, 25; 2011, 78), the understanding of the human as a more complex elaboration of life in general (Grosz $2011,13)$, and the idea that sexual selection partly drives the differentiation of species (Grosz 2005, 31; 2011, 141). Given Grosz's Deleuzian heritage, then, it is already evident that her method is anything but naturalist; in constructing an ontology of biology, she aims for novelty and a transformative role rather than empirical adequacy.

Yet Grosz must have something more than a Deleuzian understanding of philosophy in mind. For Deleuze and Guattari, the ultimate value of a concept can be 
determined only after the fact, according to the success or otherwise it has in reaching people and pointing to a different future (Patton 1996, 14). In contrast, Grosz explicitly aims for a feminist ontology, and her feminist goals are posited beforehand as desiderata for a feminist ontology. This feminist approach to ontology can be seen to derive from Grosz's simultaneous adoption of an Irigarayan approach to philosophy (Grosz 2017). ${ }^{3}$

Irigaray is notorious for her argument that, roughly put, ontology must be transformed in order to end the oppression of women. Influenced by Heidegger, Irigaray argues that Western metaphysics ${ }^{4}$ has been dominated by a substance or object ontology, in which the world is seen to be occupied by individual, independent objects to which a subject relates. Although Irigaray agrees with Heidegger concerning the way Western metaphysics has distanced humans from Being and nature (Heidegger 1977; cf. Fielding 2003), she argues that a substance ontology also excludes sexual difference. By positing a universal subjectivity and a homogeneous set of objects, Irigaray claims, substance ontology denies the possibility that subjects and their relations to objects are fundamentally sexually differentiated. Women as different subjects are therefore excluded by Western metaphysics from their own proper subjectivity and forced to take up subjectivity in relation to the masculine order. Thus, Irigaray makes the revolutionary move to argue against substance ontology on the grounds that it contributes to the exclusion and oppression of women.

In response to faulty Western metaphysics, Irigaray develops an alternative ontology: a metaphysics of fluids or a process ontology as opposed to a metaphysics of objects or substance ontology (for example, Irigaray 1985, chapter 6; cf. Murphy 2001; Stone 2003; Young 2005, 81; Stone 2015). Drawing on the cosmologies of the pre-Socratics, philosophies from India and China, and the phenomenology of the female body, Irigaray conceives of matter as active, dynamic, and sexually differentiated. What results is an ontology that can readily appear mystical or essentialist, replete with descriptions of mysterious fluid forces to which women are somehow intrinsically related. Relatedly, it can seem that Irigaray is ignoring or blatantly contradicting scientific facts about nature.

However, echoing in many ways Patton's and Colebrook's characterization of the Deleuzian task of concept-creation, Alison Stone insists that Irigaray's ontology of nature must be interpreted in light of its phenomenological and ethical goals rather than its scientific adequacy (Stone 2015, 118). First, for Irigaray an ontology of independent subjects relating to causally interacting but only superficially changing objects conflicts with our firsthand experience of the world. In contrast, Irigaray claims that a fluid metaphysics accords more with our lived experience as bodily, changing beings. In this sense, Stone elaborates, Irigaray is following the phenomenological tradition in which scientific accounts of the world are abstractions from and secondary to the understanding of the world as we live it (Stone 2003, 69).

Second, as well as aiming for phenomenological adequacy, Irigaray argues that her metaphysics of fluids will bring about a more ethical way of being in the world. According to Irigaray, seeing the world as dynamic and unpredictable involves acknowledging the agency and sensitivity of nature and that it escapes our total 
domination. And seeing the world in this way will, Stone explains, encourage us to "live more humbly, less hubristically" (Stone 2015, 121). In addition, Irigaray develops her ontology to allow for the development of sexual difference with the specific aim to foster positive relations among sexed human subjects. Thus, Irigaray argues that her ontology will lead to a more ethically responsible way of being in the world.

For Irigaray, then, ontology should be developed with a view to the way it will affect humans and their relations with one another and the world around them. Iris Young sums up Irigaray's thoughts on the matter:

The point is that a metaphysics [or ontology] of self-identical objects has clear ties to the domination of nature in which the domination of women has been implicated because culture has projected onto us identification with the abject body. It makes a difference how we think about beings in the world, and we can make choices about it that seem to have political [and ethical] implications. (Young 2005, 81)

In Irigaray's understanding of philosophy, in other words, the way we understand ourselves and live our lives is bound up with a broader understanding of and interaction with reality. As a consequence, for Irigaray, ontology is ultimately answerable to ethical and political standards, and not to scientific ones. Thus, as Grosz puts it, Irigaray understands philosophy as "ontology/ethics/politics" (Grosz 2017, 18), or more simply "onto-ethics" (16).

Grosz takes up this task of onto-ethics from Irigaray and Deleuze and Guattari. Though Grosz consistently stresses novelty as an important criterion, ${ }^{5}$ her positing of substantive goals for philosophy differentiates her approach from that of Deleuze and Guattari. Grosz therefore follows Irigaray in her attempt to develop an ontology of biology that satisfies specific feminist desiderata. ${ }^{6}$ In the next section I use this understanding of Grosz's project to evaluate her ontology on its own terms. Ultimately, I argue that, though her ontology of biology achieves some feminist goals, it also reproduces an ethically and politically problematic understanding of the nature of the organism in contrast to its environment.

\section{Reevaluating Grosz's Onto-Ethics}

Understanding Grosz's nonnaturalistic approach calls into question the evaluative frameworks of those critics who focus on criticizing Grosz for her inattention to empirical evidence or for her uncritical and dependent attitude toward the biological sciences. Instead, it suggests that Grosz's ontology should be evaluated in a Deleuzian-Irigarayan fashion, according to its generation of new concepts and its ability to achieve feminist ethical and political goals. Employing this alternative evaluative framework brings new considerations to bear on Grosz's ontology of biology and points to a novel avenue for critique.

In general, Grosz's substantive aim in creating a feminist ontology of biology is to combat the exclusion and oppression of women and to enable activities that have 
this as their aim. For instance, Grosz argues that feminist theory must develop a positive concept of difference to replace that of identity, since the latter contributes to the oppression of women through its denial of different subjectivities (for example, Grosz 2011, 89). She also discusses in many places the need to prioritize ontology and nature rather than epistemology and culture, since without ontology and an understanding of nature we do not have an appropriately complex and complete understanding of how feminist change can take place (for example, Grosz 2004, 2; 2005, 6; 2011, 84). Finally, Grosz aims to articulate, she states, "something like a new metaphysics [or ontology], a new way of understanding what is in terms more relevant to women and their interests than previous models offered." (Grosz 2010, 101; second emphasis mine)

More specifically, since her early work, Grosz has situated her ontology of biology within the feminist project to challenge biological determinism and essentialism while also according significance to biological matter as an important aspect of our reality (Grosz 1994, 14-18). Grosz argues that viewing biological matter as inert leaves intact the foundations of biological determinism and essentialism, since in both of these discourses it is the unchanging features of biology that determine or define human traits and behavior. To combat biological determinism and essentialism, Grosz calls on feminists to understand biological matter in terms of unpredictability and change. If biological materiality is a matter of the continual, unpredictable production of difference, then anything that happened in evolutionary history need not continue into the future. It is these feminist goals that Grosz has in mind in her reading of Darwin as a philosopher of becoming and of difference and her use of his theories of natural and sexual selection to support her ontology of biology. ${ }^{7}$

Though Grosz's ontology meets the feminist goals of elaborating a positive concept of difference, developing an understanding of nature that can inform attempts at feminist change, and combating biological determinism and essentialism, it also relies on a particular understanding of biology that is problematic in its own right. Working within a Darwinian framework, Grosz tends to locate the production of difference within organisms, while the environment becomes the locus for regularity and stasis, as both resource and constraint. For instance, and in a quite standard format that is still taught to biology students, ${ }^{8}$ Grosz characterizes evolution in terms of three requirements: for evolution to take place, there must be (1) individual variation, (2) the reproductive proliferation of individuals, and (3) selection of variants (Grosz 2004, 32). Whereas the first two factors are internal generative forces, dynamic and unpredictable, selection is typically seen in terms of fixed external resources and constraints. It is the environment that selects organisms for their fitness, according value to certain traits and constraining the kinds of differences that are reproduced in the next generation $(33 ; 42-48)$.

Grosz assumes this Darwinian picture in which the environment is the site of stable and regular resources and constraints, whereas the lively generation of difference is located within the organism and its reproduction. Yet there are at least two problems with this picture for feminist ethical and political goals. On the one hand, 
Grosz perpetuates a vision of bodies as ultimately flexible and pliable and thus denies both bodily fixity and bodily resistance. On the other, she reintroduces a particular version of the nature/culture dichotomy. These two aspects of the organism-environment picture that Grosz takes on from Darwin generate serious problems for the ethical and political suitability of Grosz's ontology.

First, seeing the organism only in terms of the dynamic, unpredictable production of difference marginalizes or disregards instances of stability and regularity in the organism itself. In Grosz's Darwinian framework, there seems to be little place for bodily systems that fail to generate dynamic, unpredictable differences, bodies that remain "stuck" in certain forms or states, or organisms that refuse to be shaped by the environments in which they find themselves. Instead, viewing the organism as the site of the production of differences readily leads to the idea that bodies are ultimately flexible and pliable.

The idea of bodies and organisms as flexible has serious implications for the ability of Grosz's theory to do justice to experiences of disability and illness, in which bodies often do not conform to the demands of their surroundings. Since the 1980s, theoretical models of disability and illness have been dominated by social constructionism, presenting the environment as the source of constraint and experiences of fixity or restriction (Shakespeare 2006). However, recent disability theorists have become dissatisfied with the way that social constructionists posit an ultimately flexible body that is shaped by these environmental constraints. As Tobin Siebers puts it, "the body posited by social constructionism is a body built for pleasure, a body infinitely teachable and adaptable" (Siebers 2016, 176). In response, disability theorists have argued that representations of the body must include acknowledgment of the real physical and intellectual difficulties experienced by people with disabilities. Although these cases could be recuperated into Grosz's ontology as instances of bodies generating differences from the population norm, this would still require disregarding the experiences of fixity and being stuck that illness and disability often engender.

In addition, Catherine Malabou argues that viewing bodies as flexible denies the possibility of bodily resistance to exploitation within biopolitical regimes (Malabou 2016). In developing this point, Malabou cites theorists such as Michel Foucault, Giorgio Agamben, and Roberto Esposito who theorize biopolitics as the gradual inclusion of the body's biological features and processes into the political realm that has occurred since the eighteenth century. Malabou argues that such theorists tend to view biological matter only in terms of how it is taken over and shaped by political and symbolic forces. Biological matter is thus seen as ultimately the malleable material readily available for training and regulating toward political ends, rather than as a possible source for resistance to such biopolitical control and regulation.

Malabou objects to such a view, arguing that it ignores the power of biological matter and thus dismisses an important possible site for political resistance and change. In addition, viewing bodily matter as ultimately flexible and malleable supports the very regulation and exploitation exerted in biopolitical regimes upon and through the body. Thus, Malabou argues that in a certain sense such theorists enable biopolitics, which is seen as able to "take place without tension because the 
biological is deprived of the right to respond and appears to flow simply into the mold of power" (Malabou 2016, 430). ${ }^{9}$ In contrast to the malleable body, Malabou calls for an understanding of the organism as itself "an interactive space" (433), a site where faithful transmission and possible transformation coincide. This combination of internal constraint and transformability, akin to Malabou's concept of plasticity, enables the organism to act as a site for resistance and disruption to biopolitical regimes.

Though Grosz's understanding of biological matter certainly differs from that of thinkers like Foucault and Agamben, the way she locates constraint, regularity, and so on solely in the environment tends to repeat a similar gesture, constructing the organism as flexible, malleable matter for political regulation and control. Grosz's ontology of biology therefore tends to unwittingly support the biopolitical regulation and exploitation of bodies. Such a failing is especially important for a feminist, since biopolitical regimes are often implicated in the perpetuation of the oppression of women (Deutscher 2010, 2013). In unwittingly reinforcing biopolitics, then, Grosz's ontology does not adequately challenge women's oppression. In contrast, an ontology like Malabou's, which lends greater weight to the interaction between internal constraint and transformability, might be preferable.

Along with its construal of bodies as flexible, Grosz's ontology also appears to replicate a particular version of the nature/culture dichotomy. For Grosz, as for many feminist philosophers, the nature/culture dichotomy is tied up with the oppression and exclusion of women. To tackle this dichotomy is therefore a crucial task for feminist philosophy. In her own work, Grosz attempts to destabilize the nature/culture binary by arguing that cultural processes also involve a process of evolution (Grosz 2004, chapter 2). However, the distinction between the organism and its environment, inherited from Darwin, seems to reinstall the problematic dichotomy. In Grosz's ontology the environment appears as distinct from the organism and as the limiting, restricting force on the organism's production of difference. Thus, naturein the form of the difference-producing organism - is viewed as distinct from and in conflict with culture - in the form of the limiting environment. Such a reinstatement of the nature/culture dichotomy, and the implications this has for the feminist project, is another mark against the ethical and political suitability of Grosz's ontology of biology.

In addition to Malabou's concept of plasticity, another understanding of biological matter that could perhaps be more ethically and politically sound can be derived from evo-devo (evolutionary-developmental) theories. Evo-devo approaches such as developmental systems biology arose in response to the dominance of neo-Darwinian and gene-centric understandings of evolutionary theory and biology more generally (for example, Oyama, Griffiths, and Gray 2003; Jablonka and Lamb 2014). They place strong emphasis on the interdependency between organism and environment in such a way that they are sites of both change and fixity, regularity and unpredictability, in the constant, interactive, and interrelated processes of development and evolution. Evo-devo approaches could provide a more suitable framework for a feminist understanding of biological matter, one that does not reinstate a problematic nature/ 
culture binary but rather conceives of organisms and their environment as interdependent and co-constitutive, involved in complex interplays of constraint and transformation.

Evaluating Grosz's ontology of biology within a Deleuzian-Irigarayan evaluative framework illustrates its important feminist achievements, generating an understanding of biology that challenges biological determinism and essentialism and that can inform efforts at feminist change. Yet Grosz's ontology also reproduces a Darwinian understanding of the environment as the sole limiting, constraining force on the generative power of the organism. This in turn excludes experiences of bodily fixity and limitation in disability and illness, and in addition presents an understanding of the organism as malleable material for biopolitical regimes to control and exploit. In addition, the organism-environment distinction reinstates a version of the ever-problematic nature/culture dichotomy. This is not to say that Grosz's ontology must be rejected as ethically and politically bankrupt. Rather, the important elements of Grosz's ontology of biology, especially its focus on unpredictability and change, could likely be productively combined with perspectives that reconstruct the organism-environment relation in terms of complex interplays of internal and external constraints and transformation. ${ }^{10}$ This combination of perspectives would be valuable not necessarily because it would be more in touch with empirical data, but because it would produce a more ethically and politically suitable ontology of biology.

\section{Toward a Feminist Onto-Ethics of Biology}

Grosz's biological turn has produced an important and novel feminist reading of Darwin's theory of evolution. Drawing upon Darwin's ideas about natural and sexual selection, Grosz elaborated an ontology of biological matter in terms of the continuous, unpredictable production of difference. Grosz's use of Darwin has typically been interpreted as methodologically naturalist, that is, as an attempt to ground her ontology on empirical evidence. As a consequence, some commentators have pointed out the empirical failings of Grosz's account, and others have criticized her naturalist approach as naïve and dangerous to feminist thought. An exception to this trend, Weinstein has advocated reassessing Grosz's ontology in light of its potential positive effects on feminist theory, rather than its reliance on empirical sources. Supporting Weinstein's call to shift away from methodological naturalist interpretations of Grosz's work, I showed that Grosz's own Irigarayan-Deleuzian understanding of philosophy places ethical and political considerations at the fore, rather than aiming for empirical adequacy.

Assessing Grosz on her own terms, her ontology can be seen to provide an understanding of biology that can tackle biological determinism and essentialism and inform efforts at feminist change. However, Grosz's adoption of a Darwinian picture of the organism as the site of variation in contrast to the fixed selective environment brings with it its own ethical and political problems. Specifically, Grosz marginalizes instances of both bodily fixity and bodily resistance, as well as reproducing a certain 
version of the nature/culture dichotomy. Other perspectives on the organism-environment relation, such as Malabou's concept of plasticity and evo-devo theories, can potentially inform a more ethically and politically appropriate feminist ontology, a prospect that deserves further investigation.

Perhaps the most valuable contribution Grosz makes is her insistence that ontology is not a neutral matter of study but rather a fundamentally ethical and political issue. As such, Grosz can be aligned with the approach of many new materialists, who often justify their materialist ontologies based on political effectiveness (see Alaimo and Hekman 2008; Coole and Frost 2010; Van der Tuin and Dolphijn 2012). New materialists place a greater emphasis on addressing postmillennial problems such as those generated by climate change and new genetic technologies (for example, Coole and Frost 2010), but they also often agree with Grosz in combating traditional feminist problems such as biological essentialism and determinism. However, there is a tendency among new materialists, exhibited in the very critique of Grosz's work, to fall back on empirical standards for ontology and to thereby overlook ethical and political considerations. ${ }^{11}$ Grosz's explicitly ethical and political approach to philosophy can serve as a corrective to this tendency.

Important tasks remain for constructing a satisfactory feminist ontology of biology. Grosz's philosophical reading of Darwin represents an important first step, and her highlighting of ethical and political considerations for ontology can lead the way. Here I have indicated possible sources for more sensitive approaches to the relationship between the organism and the environment, but their full ontological implications remain to be developed. Finally, it remains to be seen what role empirical data should play for ontology. Although Grosz's work is helpful in stressing the importance of ethical and political standards, we must consider whether and how empirical adequacy should be joined with ethical and political considerations in developing a feminist ontology of biology.

\section{NOTES}

I would like to thank Veronica Vasterling for her tremendous support and encouragement; without her, this article would not have come to fruition. Thanks also to those who commented on and discussed earlier drafts, especially Anya Topolski, Iris van der Tuin, and two anonymous and dedicated reviewers.

1. Convergent evolution is the process whereby species with different backgrounds come to resemble one another due to the selective advantage conferred by a particular form in a shared environment. For example, the Australian sugar glider and the American flying squirrel both separately evolved to have remarkably similar wing-like flaps between their fore and hind legs to enable them to glide between trees in densely forested areas.

2. The term methodological naturalism is not in widespread use in philosophy and has not been explicitly applied to Grosz. Perhaps more common terms would be biologism or scientism. However, these terms tend to be associated with philosophical approaches that look to the most up-to-date scientific theories and results. The term methodological naturalism is valuable since it places clear emphasis on the question of methodology, as well as 
capturing just what commentators interpret Grosz as doing in her ontology of biology, namely appealing to empirical evidence (but not evidence from contemporary science).

3. Grosz is not alone in combining Deleuze with Irigaray; a number of feminist theorists, most notably Rosi Braidotti, have developed similar approaches (for example, Braidotti 2006). See Pulkkinen 2017 for a discussion of the tensions between Deleuzian and Irigarayan philosophical frameworks.

4. In this context, and in the rest of the present article, metaphysics can be understood as the philosophical field or tradition in which ontology is developed, as in "Western metaphysics" or alternatively as simply equivalent to ontology, as in "metaphysics of fluids."

5. Grosz urges us to redirect thought into "creating, inventing, conceptualizing what has never existed before" (Grosz 2017, 23; see also 2011, 168). "At its best, feminist theory is about the invention of the new: new practices, new positions, new projects, new techniques, new values" (Grosz 2011, 83; emphasis in original; see also 2005, 2; 2010; Grosz and Hill 2017, 7)

6. On the other hand, it is not clear whether Grosz would agree with Irigaray on the importance of phenomenological adequacy. Though in her early work she used phenomenology productively, her more recent work has exhibited more ambivalence regarding the relevance of phenomenology. In this period, Grosz refers to her preferred "philosophy of becoming" as "an alternative to the traditions of liberal political thought, phenomenology from its Hegelian to its contemporary forms, and structuralism and poststructuralism" (Grosz 2011, 5). At other times, though, Grosz seems to approve of the phenomenological approach in Irigaray's work, with its basis on lived experience rather than objective knowledge of the body (145-46). I will leave the question of phenomenological adequacy unresolved, since the mere positing of feminist ethical and political goals already shifts Grosz away from methodological naturalism.

7. It is interesting to note that, as Grosz herself recognizes (Grosz 2011, chapter 7), Grosz's ontology of biological matter as dynamic and unpredictable is remarkably similar to Irigaray's process ontology of nature. Irigaray's and Grosz's moves to dynamize biological matter are also not unique. Many new materialists, for instance, have made similar claims as part of the general trend to disrupt the understanding of biological matter, and matter more generally, as fixed and passive (for example Coole and Frost 2010).

8. One that could be attributed to geneticist Richard Lewontin (Godfrey-Smith 2014, 30).

9. Malabou is perhaps too quick to dismiss some of the biopolitical theorists. Roberto Esposito, for instance, has drawn on certain understandings of biological matter precisely as a possible source for disrupting negative biopolitics (see Esposito 2011).

10. I leave aside the much-discussed question of sexual difference in order to focus on Grosz's ontology of biology as the continual, unpredictable generation of differences. A full evaluation of Grosz's biological turn would therefore require considering the criticism of Irigarayan theories of sexual difference as heterosexist and racist or ethnocentrist (for a good overview of these criticisms, see Jones 2011, chapter 6).

11. For a striking example of this tendency to slide into solely empirical standards for ontology, see Hird's survey of feminist new materialisms (Hird 2009b), where "engagement with matter" becomes "engagement with science" without comment. 


\section{REFERENCES}

Alaimo, Stacy, and Susan Hekman. 2008. Introduction: Emerging models of materiality in feminist theory. In Material feminisms, ed. Stacy Alaimo and Susan Hekman. Bloomington and Indianapolis: Indiana University Press.

Braidotti, Rosi. 2006. Transpositions: On nomadic ethics. Cambridge, UK, Malden, Mass.: Polity.

Butler, Rex. 2016. Deleuze and Guattari's 'What is Philosophy?' A reader's guide. London and New York: Bloomsbury Publishing.

Colebrook, Claire. 2002. Understanding Deleuze. Sydney: Allen \& Unwin.

Coole, Diana, and Samantha Frost. 2010. Introducing the new materialisms. In New materialisms: Ontology, agency, and politics, ed. Diana Coole and Samantha Frost. Durham, N.C., and London: Duke University Press.

Deleuze, Gilles, and Félix Guattari. 1994. What is philosophy? Trans. Hugh Tomlinson and Graham Burchell. New York: Columbia University Press.

Deutscher, Penelope. 2010. Reproductive politics, biopolitics and auto-immunity: From Foucault to Esposito. Journal of Bioethical Inquiry 7 (2): 217-26.

- 2013. The membrane and the diaphragm: Derrida and Esposito on immunity, community, and birth. Angelaki 18 (3): 49-68.

Esposito, Roberto. 2011. Immunitas: The protection and negation of life. Cambridge, UK, and Malden, Mass.: Polity.

Fielding, Helen. 2003. Questioning nature: Irigaray, Heidegger and the potentiality of matter. Continental Philosophy Review 36 (1): 1-26.

Godfrey-Smith, Peter. 2014. Philosophy of biology. Princeton and Oxford: Princeton University Press.

Grosz, Elizabeth. 1994. Volatile bodies: Toward a corporeal feminism. Bloomington and Indianapolis: Indiana University Press.

- 2004. The nick of time: Politics, evolution, and the untimely. Sydney: Allen \& Unwin.

- 2005. Time travels: Feminism, nature, power. Sydney: Allen \& Unwin.

- 2010. The practice of feminist theory. Differences 21 (1): 94-108.

. 2011. Becoming undone: Darwinian reflections on life, politics, and art. Durham, N.C., and London: Duke University Press.

- 2017. Irigaray, the untimely, and the constitution of an onto-ethics. Australian Feminist Law Journal 43 (1): 15-24.

Grosz, Elizabeth, and Rebecca Hill. 2017. Onto-ethics and difference: An interview with Elizabeth Grosz. Australian Feminist Law Journal 43 (1): 5-14.

Heidegger, Martin. 1977. The question concerning technology, and other essays. Trans. William Lovitt. New York and London: Garland Publishing.

Hird, Myra. 2009a. The origins of sociable life: Evolution after science studies. Basingstoke, UK, and New York: Palgrave MacMillan.

- 2009b. Review: Feminist engagements with matter. Feminist Studies 35 (2): 32946.

Irigaray, Luce. 1985. This sex which is not one. Trans. Catherine Porter and Carolyn Burke. Ithaca, N.Y: Cornell University Press. 
Jablonka, Eva, and Marion J. Lamb. 2014. Evolution in four dimensions: Genetic, epigenetic, behavioral, and symbolic variation in the history of life. Revised edition. Cambridge, Mass., and London: MIT press.

Jagger, Gill. 2015. The new materialism and sexual difference. Signs: Journal of Women in Culture and Society 40 (2): 321-42.

Jones, Rachel. 2011. Irigaray: Towards a sexuate philosophy. Cambridge, UK, and Malden, Mass: Polity.

Malabou, Catherine. 2016. One life only: Biological resistance, political resistance. Trans. Carolyn Shread. Critical Inquiry 42 (3): 429-38.

McNeil, Maureen. 2010. Post-millennial feminist theory: Encounters with humanism, materialism, critique, nature, biology and Darwin. Journal for Cultural Research 14 (4): 427-37.

Murphy, Ann. 2001. The enigma of the natural in Luce Irigaray. Philosophy Today 45 (Supplement): 75-82.

Oyama, Susan, Paul E. Griffiths, and Russell D. Gray. 2003. Cycles of contingency: Developmental systems and evolution. Cambridge, Mass., and London: MIT Press.

Papineau, David. 2016. Naturalism. In The Stanford encyclopedia of philosophy, Winter 2016, ed. Edward N. Zalta. Metaphysics Research Lab, Stanford University.

Parisi, Luciana. 2010. Event and evolution. Southern Journal of Philosophy 48 (s1): 147-64.

Patton, Paul. 1996. Introduction. In Deleuze: A critical reader, ed. Paul Patton. Malden, Mass.: Blackwell.

Pulkkinen, Tuija. 2017. The role of Darwin in Elizabeth Grosz's Deleuzian feminist theory: Sexual difference, ontology, and intervention. Hypatia 32 (2): 279-95.

Shakespeare, Tom. 2016. The social model of disability. In The disability studies reader, ed. Lennard J. Davis. 2nd ed. New York and Oxford: Routledge.

Siebers, Tobin. 2016. Disability in theory: From social constructionism to the new realism of the body. In The disability studies reader, ed. Lennard J. Davis. $2^{\text {nd }}$ ed. New York and Oxford: Routledge.

Smith, Daniel, and John Protevi. 2018. Gilles Deleuze. In The Stanford encyclopedia of philosophy, Spring 2018, ed. Edward N. Zalta. Metaphysics Research Lab, Stanford University.

Stone, Alison. 2003. The sex of nature: A reinterpretation of Irigaray's metaphysics and political thought. Hypatia 18 (3): 60-84.

- 2015. Irigaray's ecological phenomenology: Towards an elemental materialism. Journal of the British Society for Phenomenology 46 (2): 117-31.

Van der Tuin, Iris, and Rick Dolphijn. 2012. New materialism: Interviews and cartographies. London: Open Humanities Press.

Weinstein, Jami. 2010. A requiem to sexual difference: A response to Luciana Parisi's "Event and Evolution". Southern Journal of Philosophy 48 (s1): 165-87.

Young, Iris Marion. 2005. On female body experience: "Throwing like a girl" and other essays. Oxford: Oxford University Press. 